\title{
Analysis of Hybrid Solar Wind Energy System with Multilevel Inverter Control at the Load End
}

\author{
Pooja Mahajan \\ M. Tech Scholar \\ Oriental College of Technology \\ Bhopal (M.P) India \\ pooja25mahajan@gmail.com
}

\author{
Urmila Soni \\ Assistant Professor \\ Oriental College of Technology \\ Bhopal (M.P) India \\ urmilasoni@oriental.ac.in
}

\begin{abstract}
Integrating all energy supplies to the dc bus requires the use of power electronic devices. The effectiveness of a MLI with two variable generating units has been researched, and the performance has been enhanced through designed regulation. This paper discusses the system was processed to develop a threephase voltage output, a magnitude of nearly $230 \mathrm{~V}$ at the Multi level inverter side and a smooth waveform at the load side. The framework becomes more dependable after it is integrated with the grid.
\end{abstract}

Keywords: Renewable Energy, Multilevel Inverters, Hybrid Renewable Energy Systems,

\section{INTRODUCTION}

Countries are achieving their huge development objectives by giving facilities such as clean, safeguard, dependable, and cost effective energy with the help of renewable power generation. Due to the obvious insufficiency of coal, gas, fossil feuls, there is a rise in fuel costing, and toxic pollutants emitted from the ignition of fossil fuels, petroleum products have become unaffordable and unprofitable for power generation. The urban expansion on the basis of industries of the past thirty years, attributed to globalization, new technology innovations, and rapid urbanization birthrate domestic energy usage, has resulted in a dramatic rising energy requirements, particularly for electricity. This is what has resulted in a massive market imbalance in the power industry. Until another source of power is found, it is expected that the gap in production and consumption will keep increasing at exponential rate. Remoteness of grid power to distant communities and a dearth of electrification in village based areas have triggered the demand for optional energy sources.

Latest innovations in technologies based on renewable energy and power electronics inverter which are used to transform the uncontrollable power initiated from renewable energies into apparent work at the load side, Hybrid Renewable Energy Systems (HRES) are an amalgamation of multiple renewable resource or minimum one single renewable resource to source which are used earlier.
This can be grid linked up or stronger to be in stand-alone mode. The much more significant benefit of HRES would be that it makes amazing use of the operating features of renewable power initiation innovations, resulting in higher efficiency improvements than could be achieved with an individual power source.

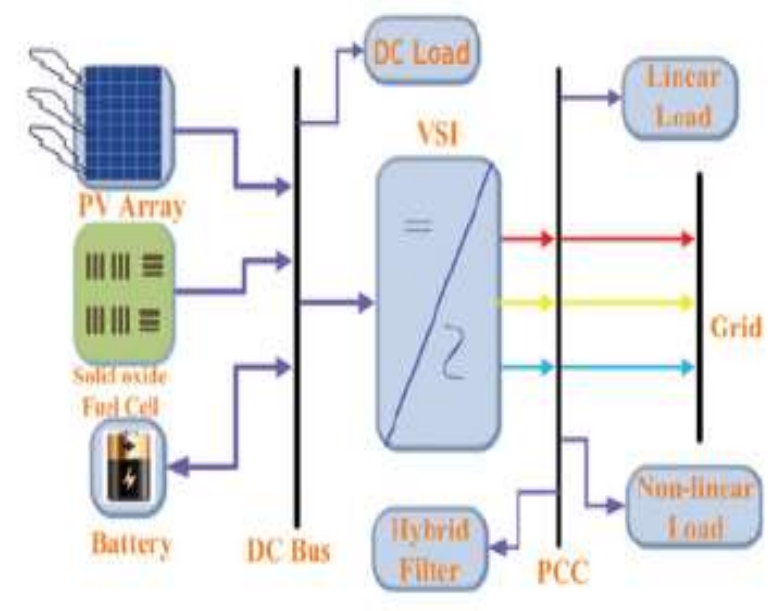

Figure 1 Hybrid system

HRES (Hybrid Renewable Energy Sources) is a type of optional energy source that combines multiple renewable energy resources. The excellent performance of initiation is achieved through the technique of hybridizing renewable resources.

\section{LITERATURE REVIEW}

Kumar Chinnaiyan $\mathbf{V}$ et al. [1] The suggested work's primary objective is to develop a power electronic converter that will mitigate power quality fluctuations. Power quality concerns have proven to be a significant area of investigation owing to the increasing use of power electronic devices for power computation. To accomplish high effectiveness, the voltage rises in response to a rise in power. The voltage rating of rapidly swapping high voltage semiconductor materials like the Insulated Gate Bipolar Transistor (IGBT) has increased 
dramatically in recent decades. And there is a demand for switching devices to be connected in series. The multilevel power converter is becoming extremely prevalent in this field. The best features of multilevel converter layouts are poorly disrupted output waves and reduced voltage stress on the power switches, reduction of electromagnetic interference on the output signals.

Hua Geng et al. [2] The consistency concerns of a straightforward motivated wind energy conversion system (WECS) relying on a permanent magnetic synchronous generator (PMSG) are addressed in this section, as well as a torque remuneration policies to strengthen grid stability. The stabilisation findings reveal that by presenting a lowfrequency oscillating configuration, the drive train developments can greatly impact system stabilization, and the stability margin can be increased by using a sluggish generator torque feedback signal or a minimal energy converter responding. In the torque feedback controller, the torque remuneration strategy involves a feed-forward compensator that is framed using the dc current pumped into the modules' dc link capacitor. The oscillating procedure is downregulated and the WECS's consistency is enhanced with this compensation. The numerical simulations substantiate the parametric study and also the strategy's small-signal and transient achievement.

F. Blaabjerg et al. [3] in this investigation of the d uring the year 2013, wind power remains the most encouraging renewable energy. In the $1980 \mathrm{~s}$, the wind turbine system (WTS) began with just few tens of kilowatts of power. Multimegawatt wind turbines, up to 6-8 megawatts, were already have various application. Wind turbines are widely used in distribution systems, and an increasing number of wind power stations that function as power plants are directly tied to transmission system. Wind power begins to be have major effects on the power grid as grid insertion and power levels of wind turbines boost progressively. To strengthen the attributes of the wind turbine and find out the appropriate for integration into the power grid, extra innovative power- producers, power electronic systems, and regulating alternatives must be presented. In the meantime, there are several evolving techniques challenges that would need to be cleared up and explored further. This paper provides a summary of the technology solutions used in wind power systems and describes some recent developments. Initially, the broad sense state of innovation and the industry is discussed.

Francisco Díaz-González et al. [4] Electric power initiated by wind turbines is damaging effects just because of the stochastic nature of wind, and this can actually impact both power quality and power system making plans. By attempting to control wind power plant outcome and supplying additional services to the power system, Energy Storage Systems (ESSs) may play an essential part in wind power implementations allowing for greater integration of wind in the system. The objective of this essay is to provide an overview from several storage technologies that can be used in wind turbine applications. Including an extensive literature survey, the study's principal targets are to introduce the core concepts, highlight the key qualities of energy storage techniques suitable for stationary implementations, and define and consider possible ESS implementations in wind power.

Suziana Ahmad et al. [5] Because of the elevated energy requirements and the diminishing supply of fossil fuels, most nations around the globe are turning to renewable renewable energy including wind, tidal, and photovoltaic (PV) for producing electric energy. Amongst which, the research of photovoltaics (PV) as an optional source of electricity has risen in popularity. The usage of a grid-connected multilevel inverter is amongst the most significant elements in a PV implementations. For integrating grid and PV applications, this research focuses on three phase diode clamped multilevel inverters, capacitor clamped multilevel inverters, and $\mathrm{H}$ cascaded bridge multilevel inverters. The control mechanisms for all these three different kinds of MLI were simulated in a Matlab-Simulink setup using multicarrier pulse width modulation (PWM). The output waves of multilevel inverters are shown, with comparisons made between them. It is suggested that the finest architecture for a grid-connected multilevel inverter for PV applications be used.

AmmarHasan et al. [6] The usage for clear and sustainable energy has sparked investigations into all kinds of renewable energy resources, along with solar energy from photovoltaic ( pv ) systems, as demonstrated in this study. Grid-connected photovoltaic systems (GCPS) are a cost-effective way to implement solar energy into the grid. The inverter is an important part of the GCPS. The converters can have a huge effect on the GCPS's actual quality, like Maximum power point tracking, total harmonic distortion (THD), and effectiveness. Multilevel inverters are among the most encouraging converter types for achieving low THD. In this article, designers suggest a novel multilevel inverter topology with the goal of improving all three measures of quality discussed above. Direct model predictive control (DMPC), a state-of-the-art control technique, is used to control the suggested configuration. They evaluated the proposed topology's performance to that of other architectures presented in the literature. One of the optimum performance, Maximum power point tracking, and voltage THD is provided by the proposed scheme.

Gerald Christoper Raj et al. [7] A innovative single-phase cascaded grid connected multilevel inverter (MLI) for trying to feed power to microgrid from renewable energy is suggested in this study (RESs). The proposed inverter can provide reduced total harmonic distortion power to a microgrid (THD). The suggested inverter is made up of two $\mathrm{H}$ bridge inverters, the top and bottom inverters, which are linked in a cascade. The upper inverter is nourished from a photovoltaic (PV) arrangement via a DC-DC enhanced converter, while the reduced inverter is fed via an uncontrolled rectifier and DC- 
DC enhance converter from a wind turbine (WT) coupled to a permanent magnet synchronous generator (PMSG). The upper inverter works at a high frequency, while the lower inverter works at the fundamental frequency. A trajectory tracking control depending maximum power point tracker (MPPT) is utilized to retrieve maximum power from the WT and PV array. The control algorithm is employed in the SPARTAN 3A digital signal processor (DSP) board, and the suggested inverter is connected to a single phase $230 \mathrm{~V}, 50 \mathrm{~Hz}$ grid. The proposed inverter is simulated with matlab/simulink, and extensive experimental findings are summarized to demonstrate its efficacy in wide range of environmental conditions.

Sangita R Nandurkar et al. [8] The modelling and simulation of a three-phase inverter in the MATLAB SIMULINK environment, which can be used in photo - voltaic grid linked systems, is the focus of this article. To incorporate a managed current into the grid, a voltage source inverter (VSI) is utilized, which is managed using a synchronous d-q reference frame. Grid frequency and phase are locked using a phase lock loop (PLL). The architecture of a low pass filter that is utilised at the inverter output to eliminate high frequency ripple is also mentioned, as well as the modelling results.

P. AkashPattanaik et al. [9] The parametric studies of a twostage converter system for incorporating PV panels with the grid is the main focus of this paper. PV panels, a boost dc-dc transformer for stepping up PV panel voltage, a VSI for converting dc to ac, and finally the grid make up the system. The Incremental Conductance algorithm is used to operate the PV panel at its maximum power point, and the system also works in a variety of different weather conditions. Frame controller is utillised to control inverter output in relation to grid synchronous reference (dq). To lock grid frequency and phase with respect to inverter output, a three-phase PLL is employed. To eliminate high frequency harmonics from the inverter output, a low pass LC filter is modelled, and a transformer is being used to offer galvanic isolation between inverter output and the grid. The simulations are all run in the MATLAB Simulink environment.

S. Kouro et al. [10] In the last 5 years, photovoltaic (PV) energy has risen at a 60 percent annual rate, surpassing onethird of total wind energy installed capacity, and is rapidly will become an important element combination in some territories and power systems. The cost of PV modules has come down, which has aided this. This expansion has prompted the evolution of traditional PV power converters from singlephase grid-tied inverters to more complex topologies in order to improve efficiency, power retrieval from modules, and serviceability without increasing costsThe framework of distinct PV plants and the PV converter configurations that have encountered real world implimentations for gridconnected systems are described in detail. In additament, new studies and evolving PV converter future technologies are mentioned, with significant benefits over current technology highlighted.

\section{METHODOLOGY}

To model components of HRES, people have designed a variety of modelling techniques. Individual elements achievement is modelled using either deterministic or stochastic methods. This section covers the fundamental modelling constructions of solar and wind energy systems, as well as the modelling of PSS control mechanisms.

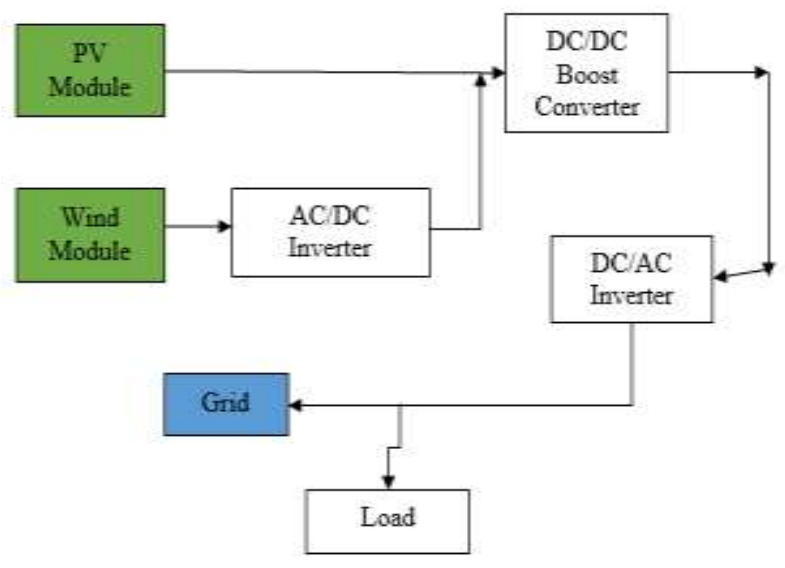

Figure 2 Proposed Hybrid energy system topology

Photovoltaic modules have a standalone operating point in which the cell's current (I) and voltage (V) produce the maximized amount of power. These numbers correlate to a specific resistance, which really is proportion of voltage and current as V/I. Figure 3 depicts a straightforward PV cell circuit design.

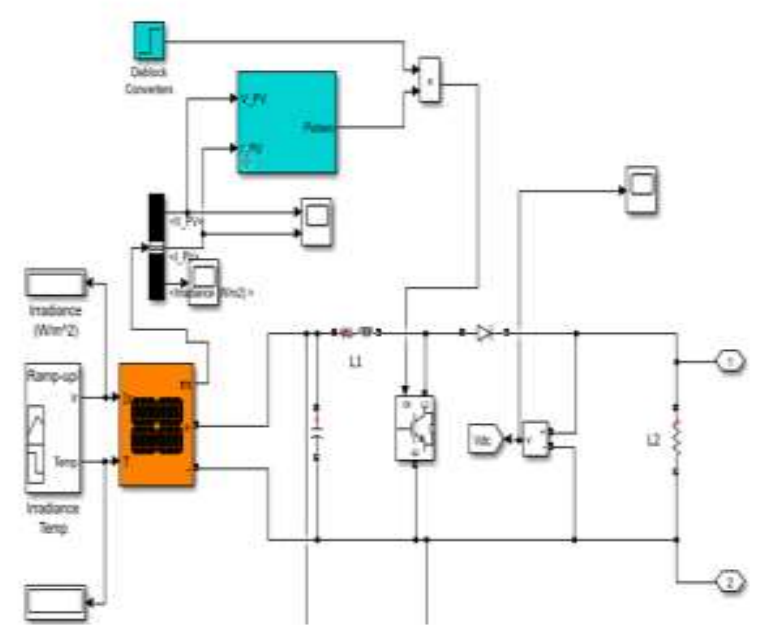

Figure 3 solar system modeling in Simulink

Wind turbine prototype with Permanent magnet synchronous motor Wind turbines are unable to capture all of the energy generated by the wind. The set of formulae have been used to model the elements of a wind turbine. The wind turbine's throughput aerodynamic power is expressed as: 


$$
P_{\text {Turbine }}=\frac{1}{2} \rho A C_{p}(\lambda, \beta) v^{3}
$$

where $\mathrm{A}$ is the area pushed by the rotor blades (in $\mathrm{m} 2$ ), $\mathrm{CP}$ is the coefficient of power conversion, and $\mathrm{v}$ is the wind speed (in $\mathrm{m} / \mathrm{s}$ ), and is the air density (typically $1.225 \mathrm{~kg} / \mathrm{m} 3$ ).

The tip-speed proportion is calculated as follows:

$$
\lambda=\frac{\omega_{m} R}{v}
$$

where $\omega_{m}$ and $R$ are the rotor angular velocity (in $\mathrm{rad} / \mathrm{sec}$ ) and rotor radium (in $\mathrm{m}$ ), respectively. The wind turbine mechanical torque output $m T$ given as:

$$
T_{m}=\frac{1}{2} \rho A C_{p}(\lambda, \beta) v^{3} \frac{1}{\omega_{m}}
$$

The power coefficient is a nonlinear function of the tip speed ratio $\lambda$ and the blade pitch angle $\beta$ (in degrees).

Then Power output is given by

$$
P_{\text {Turbine }}=\frac{1}{2} \rho A C_{p_{\max }} v^{3}
$$

A generic equation is used to model the power coefficient $C_{P}$ based on the modeling turbine characteristics described as:

$$
C_{p}=\frac{1}{2}\left(\frac{116}{\lambda_{i}}-0.4 \beta-5\right) e^{-\left(\frac{21}{\lambda_{i}}\right)}
$$

There is a particular aspect in the wind generator power attribute, MPPT, where the output power is enhanced for every wind speed. As a result of the regulation of the Wind Energy Conversion System (WECS) load, the turbine rotor operates at a varying speed, extracting highest power from the wind consistently.

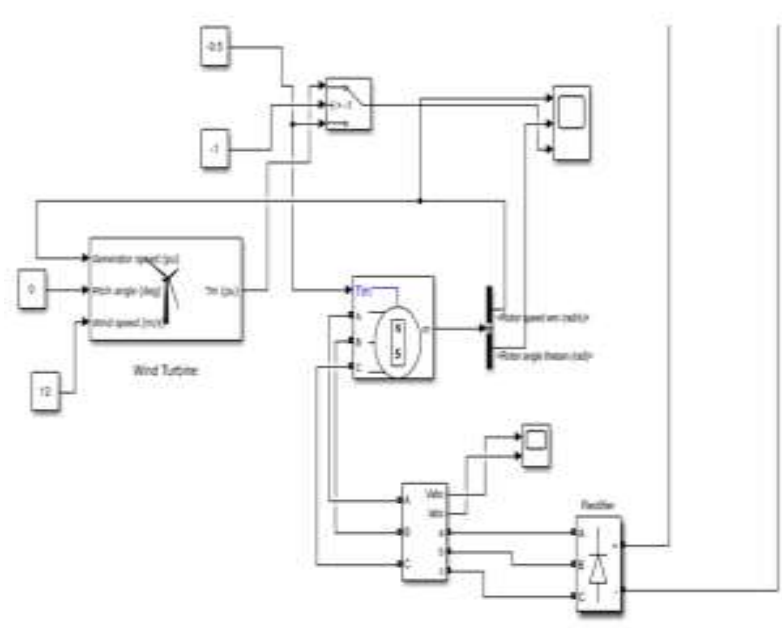

Figure 4 PMSM based wind energy system power generation

The changeable torque output wm is used in this framework, which focuses on increasing the output current and voltage waveform.
The converter is in charge of leading the PMSM and adjusting its angular speed in response to various load torques. Because the wheel motor is a synchronous permanent magnetic machine (PMSM), the electromagnetic torque demonstrated in the $\mathrm{d}-\mathrm{q}$ rotating frame is given by:

$$
T_{e}=\frac{3 p}{2}\left[\Psi_{P M} i_{q}+i_{q} i_{d}\left(L_{d}-L_{q}\right)\right]
$$

where $\mathrm{p}$ is the number of pole pairs; $\Psi_{P M}$ is the flux produced by the permanent magnet; $L_{d}$ and $L_{d}$ are respectively the direct and quadrature components of the wheel motor inductance. $i_{q}$ is the quadrature axis current and $i_{d}$ is the direct axis current.

\section{Result And Discussion}

The maximized output throughout the terminal varies as temperature and radiation change, lowering the Photovoltaic cell's effectiveness. The notion behind the maximum power point tracking working strategy is to keep the terminal voltage at a level that corresponds to the maximum power point. The MPPT's job is to keep the solar operating voltage near to the MPP in changing atmospheric circulation. This is becoming a necessary component in determining the architecture efficiency of Photo-Voltaic systems.

The flow chart of the method is given in Fig.5. from the figure it can be seen that, the algorithm tracks the change in voltage, if $\Delta \mathrm{V}=0$ than change in current $\Delta \mathrm{I}$ is tracked. If $\Delta \mathrm{I}>0$, then increase operating voltage and if $\Delta \mathrm{I}<0$, then reduction the operating voltage. If $\Delta \mathrm{V} \neq 0$, then ratio of change in voltage with respect to change in current is find out in terms of ratio of operating voltage and current. Therefore, increment and decrement in operating voltage is done to track the point of maximum power output.

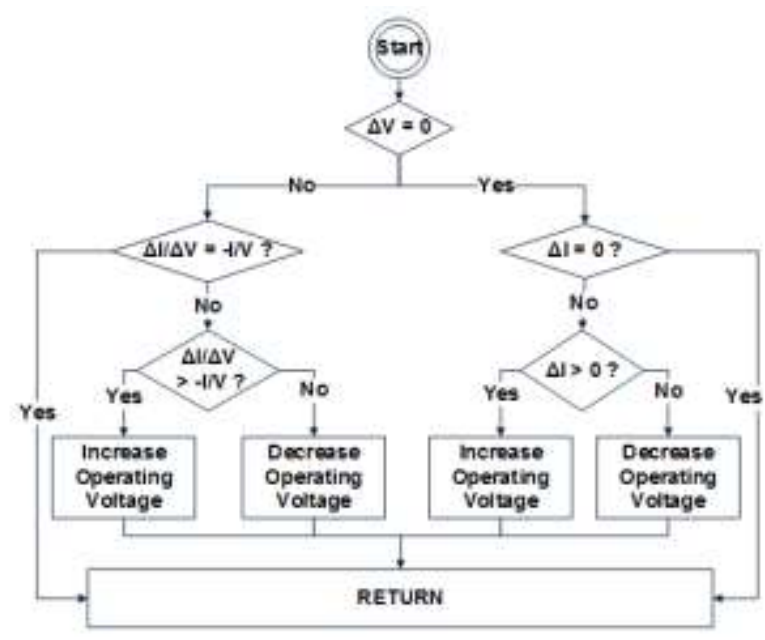

Figure 5 Flowchart of Inc. Con. Method

A boost converter, also recognized as a voltage step up converter, is a device that converts a reduced input voltage into a maximize output voltage. Figure 6 depicts the boost converter layout current circulates through the inductor (L) 
and energy is contained whenever the switch S1 is turned together by the Pulse width modulation pulse. Whenever the switch is turned off, the magnetic field energy captured in the inductor produces an induced voltage throughout the inductor, which enhances to the input voltage. The input voltage and the voltage across the inductor are connected in sequences, causing the output capacitor (Cout) to be charged to a voltage greater than the input voltage.

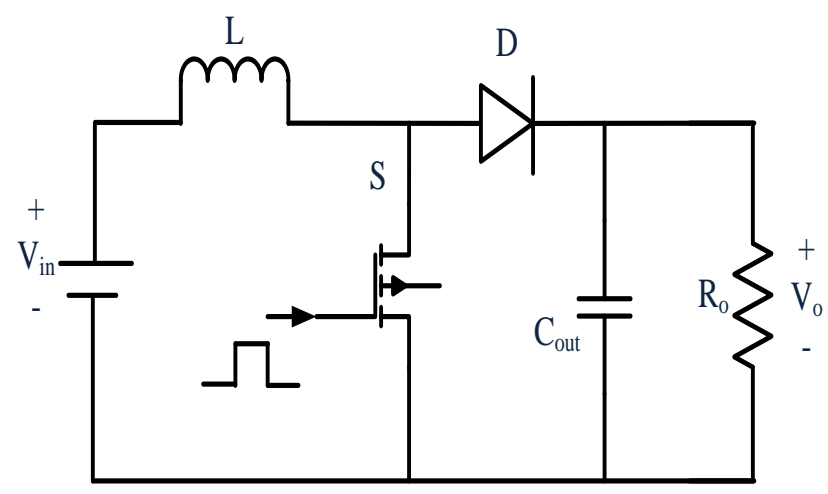

Figure 6 Circuit diagram of boost converter

A DC-DC converter controlled by high frequency switching technique, and is placed in between the solar panel and inverter, with the aim of regulating the output voltage. In the proposed work DC-DC Boost converter is used to regulate the PV output voltage. It consists of $V i$, input voltage fed from PV array, input inductance $L$ switch ' $\mathrm{S}$ ' whose triggering is controlled by PWM. The control logic for PWM is designed using MPPT based algorithm. Diode 'D' prevents the flow of current in reverse direction. $C_{\text {out }}$ is the output capacitance which make sure a more or less ripple free and constant voltage level. It consists of state of operation, ON-state and OFF-state.

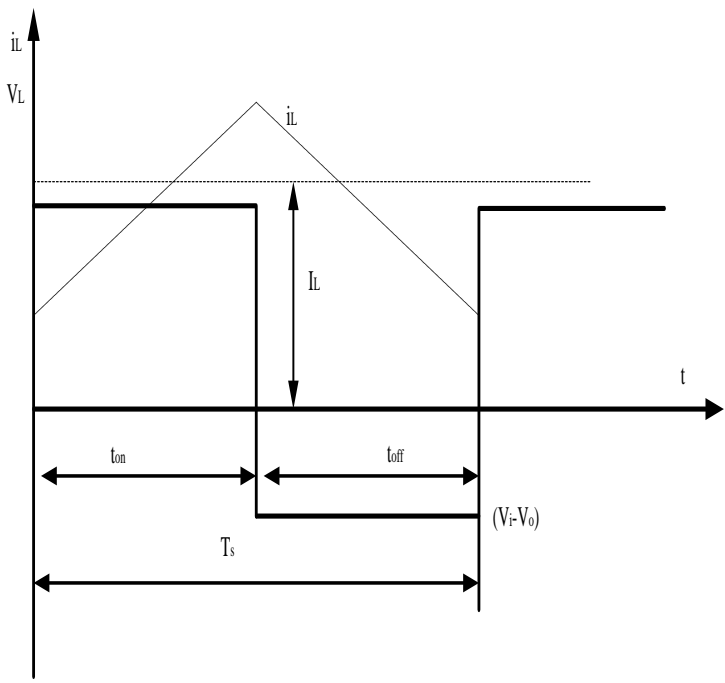

Figure 7 Voltage and current waveform of boost converter.

\begin{tabular}{|c|c|c|c|}
\hline S No. & Parameter & Expression & Value \\
\hline 1 & Duty cycle (D) & $D=1-\left(\frac{V_{\mathrm{i}}}{\mathrm{V}_{\mathrm{o}}}\right)$ & $70 \%$ \\
\hline 2 & Switching frequency & $f_{s}$ & $5 \mathrm{KHz}$ \\
\hline 3 & Load current $(I o)$ & $\frac{V_{o}}{R_{0}}=\frac{V_{i}}{R_{0}(1-D)}$ & $100 \mathrm{~A}$ \\
\hline 4 & Ripple current $\left(\Delta I_{0}\right)$ & $\Delta I_{O}=0.1 \times I_{O}$ & 0.04 \\
\hline 5 & Inductor $(L)$ & $L=\frac{V_{i} \times D}{\Delta I_{L} \times f_{s}}$ & $0.99 \mathrm{mH}$ \\
\hline 6 & Capacitor $\left(C_{\text {out }}\right)$ & $\begin{array}{l}C \\
=\frac{D}{R_{o} \times f_{s} \times 0.01}\end{array}$ & $1000 \mu \mathrm{F}$ \\
\hline
\end{tabular}

The PV generates DC power which is converted into AC using DC-AC converter to supply the load or to feed the grid. For DC-AC conversion in SECS, generally conventional voltage source inverter (VSI) is preferred. The structure of a threephase VSI comprises of six switches and a capacitor on DC side. The triggering of the switches in each of the three legs of the VSI is initiated by Pulse Width Modulation (PWM) Schem. The commonly used PWM techniques are Sinusoidal PWM (SPWM), Space Vector Modulation (SVM), and random PWM. The detailed comparison of all the PWM techniques is presented. In this research work, SPWM technique is used which is a carrier based PWM technique. In SPWM modulating signal is generated by comparing the pulses with the sine wave which helps in reducing distortion factor remarkably. The converter control is designed in synchronous reference frame (SRF) with DC voltage control and AC current/voltage control using PI controller. The Phase Locked Loop (PLL) synchronizes the control by detecting the amplitude and the phase angle vector of the grid voltage/current. 


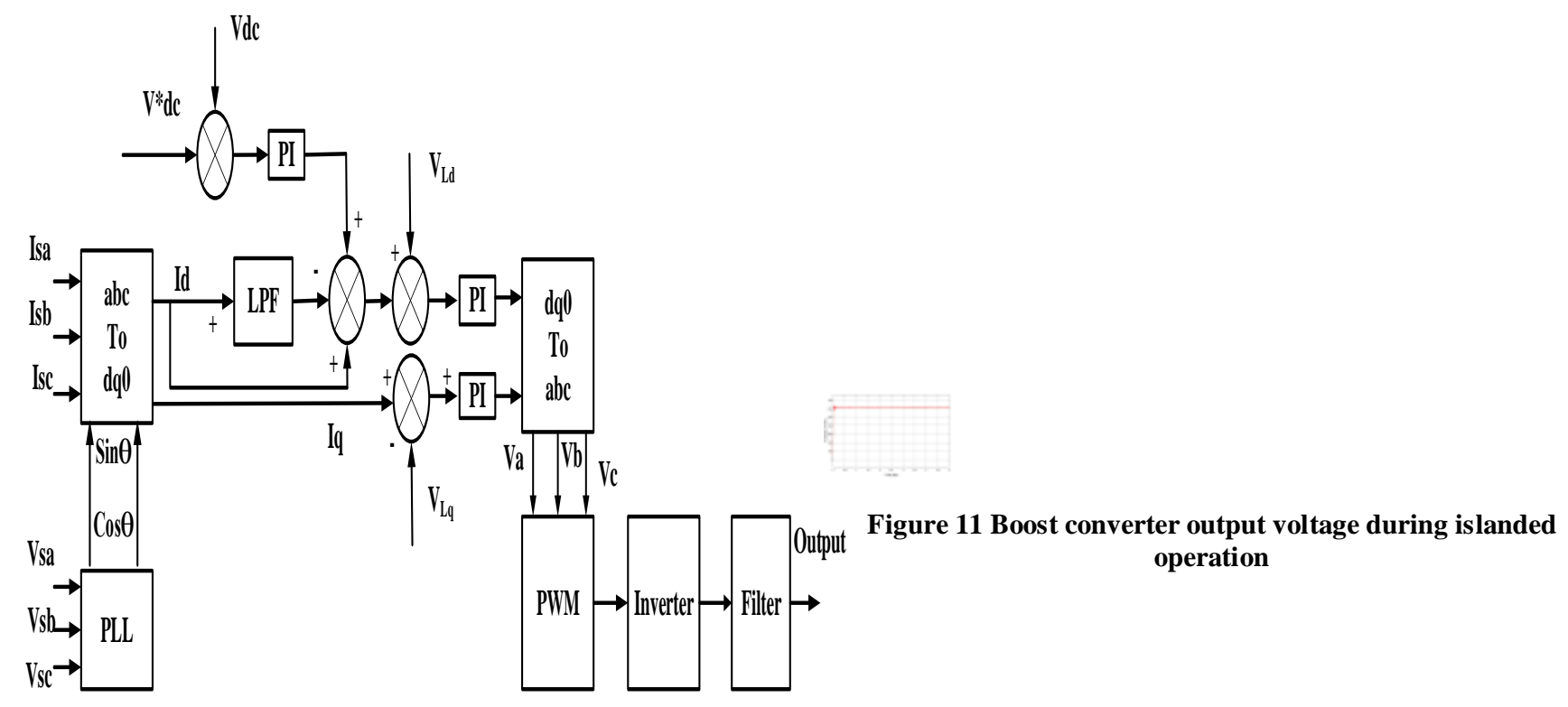

Figure 8 Inverter control

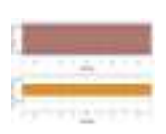

Figure 9 Voltage and current at point of grid integration

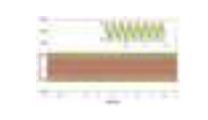

Figure 12 AC output voltage without filter in islanded condition

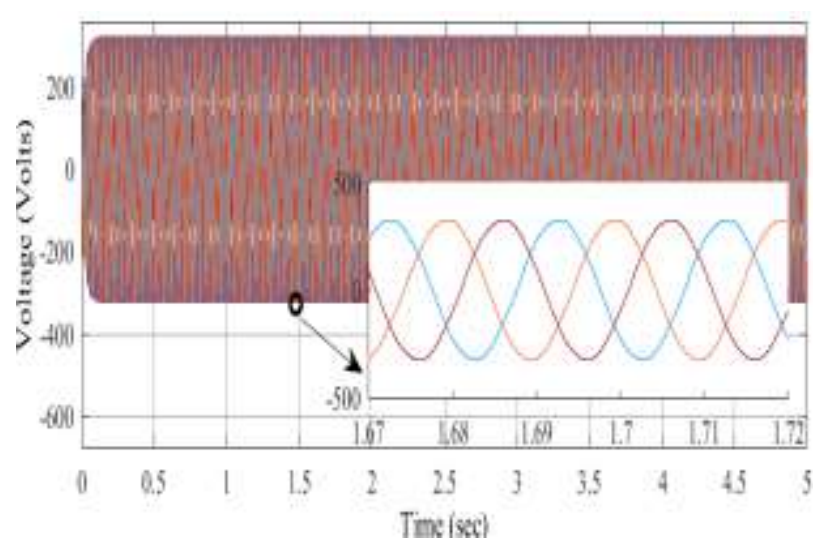

Figure 13 Output voltage for constant irradiance in SAM

Figure 10 DC voltage output of boost converter 


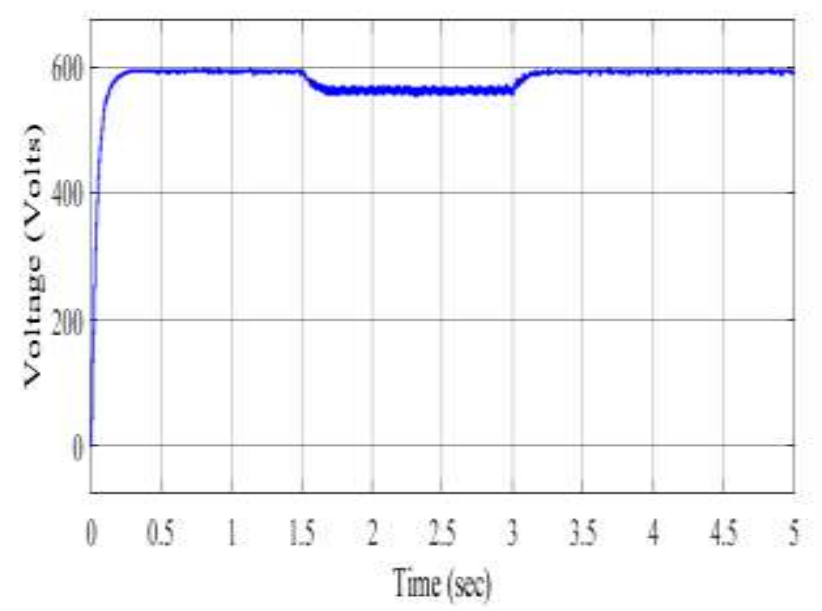

Figure 14. DC voltage for variable irradiance

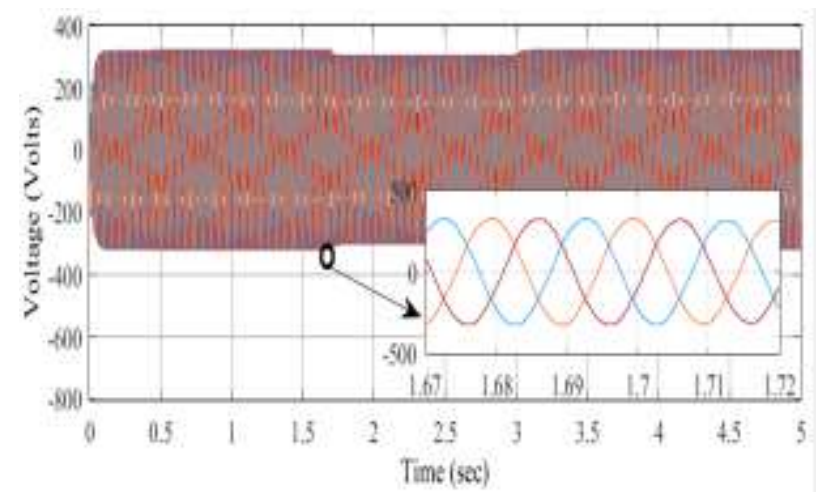

Figure 15 Output voltage for variable irradiance in SAM

\section{CONCLUSION}

A microgrid for the penetration of renewable energy sources has been envisioned. The implementation of operating optimization and power-electronics depending voltage-power regulation were created, and their functionality was illustrated using computation. Integrating all energy supplies to the dc bus requires the use of power electronics. The achievement of a multilevel inverter with two variable initiating stations has been researched, and the effectiveness has been enhanced through designed control.

The system has been designed for three phase voltage output produced at the MLI end with magnitude approximately 230 $\mathrm{V}$ and smooth waveform at the load terminal. On integration with the grid the system is made more reliable and

Operation in autonomous mode is also endorsed in compliance with the micro grid concept to maintain the program whenever the main grid interconnection is inaccessible. Throughout these times, the focus is on providing critical local loads.

\section{REFERENCES}

[1] Poorfakhraei, A., Narimani, M., \& Emadi, A. (2021). A Review of Modulation and Control Techniques for Multilevel Inverters in Traction
Applications. IEEE Access, 9, 24187-24204. https://doi.org/10.1109/ACCESS.2021.3056612

[2] Vemuganti, H. P., Sreenivasarao, D., Ganjikunta, S. K., Suryawanshi, H. M., \& Abu-Rub, H. (2021). A Survey on Reduced Switch Count Multilevel Inverters. IEEE Open Journal of the Industrial Electronics Society, 2(December 2020), 80-111. https://doi.org/10.1109/ojies.2021.3050214

[3] Odeh, C. I., Lewicki, A., \& Morawiec, M. (2021). A Single-Carrier-Based Pulse-Width Modulation Template for Cascaded H-Bridge Multilevel Inverters. IEEE Access, 9, 42182-42191. https://doi.org/10.1109/ACCESS.2021.3065743

[4] Barbie, E., Rabinovici, R., \& Kuperman, A. (2021). Analytical formulation and optimization of Weighted Total Harmonic Distortion in three-phase staircase modulated multilevel inverters. Energy, $215,119137$. https://doi.org/10.1016/j.energy.2020.119137

[5] Easley, M., Shadmand, M. B., \& Abu-Rub, H. (2021). Computationally-Efficient Optimal Control of Cascaded Multilevel Inverters with Power Balance for Energy Storage Systems. IEEE Transactions on Industrial Electronics, 68(12), 12285-12295. https://doi.org/10.1109/TIE.2020.3048281

[6] Khan, M. J. (2021). Review of Recent Trends in Optimization Techniques for Hybrid Renewable Energy System. Archives of Computational Methods in Engineering, 28(3), 1459-1469. https://doi.org/10.1007/s11831-020-09424-2

[7] Sayed, E. T., Wilberforce, T., Elsaid, K., Rabaia, M. K. H., Abdelkareem, M. A., Chae, K. J., \& Olabi, A. G. (2021). A critical review on environmental impacts of renewable energy systems and mitigation strategies: Wind, hydro, biomass and geothermal. Science of the Total Environment, 766, 144505. https://doi.org/10.1016/j.scitotenv.2020.144505

[8] Mosaad, M. I., Ramadan, H. S. M., Aljohani, M., El-Naggar, M. F., \& Ghoneim, S. S. M. (2021). Near-Optimal PI Controllers of STATCOM for Efficient Hybrid Renewable Power System. IEEE Access, 9, 34119-34130. https://doi.org/10.1109/ACCESS.2021.3058081

[9] Mudi, J., Shiva, C. K., Vedik, B., \& Mukherjee, V. (2020). Frequency Stabilization of Solar ThermalPhotovoltaic Hybrid Renewable Power Generation Using Energy Storage Devices. Iranian Journal of Science and Technology - Transactions of Electrical Engineering, 0123456789. https://doi.org/10.1007/s40998-020-00374-w 
[10] Nguyen, N. T., Matsuhashi, R., \& Vo, T. T. B. C. (2021). A design on sustainable hybrid energy systems by multi-objective optimization for aquaculture industry. Renewable Energy, 163, 1878-1894.

https://doi.org/10.1016/j.renene.2020.10.024

[11] Levenda, A. M., Behrsin, I., \& Disano, F. (2021). Renewable energy for whom? A global systematic review of the environmental justice implications of renewable energy technologies. Energy Research and Social Science, 71(October 2020), 101837. https://doi.org/10.1016/j.erss.2020.101837

[12] Al-Shahri, O. A., Ismail, F. B., Hannan, M. A., Lipu, M. S. H., Al-Shetwi, A. Q., Begum, R. A., AlMuhsen, N. F. O., \& Soujeri, E. (2021). Solar photovoltaic energy optimization methods, challenges and issues: A comprehensive review. Journal of Cleaner Production, 284, 125465. https://doi.org/10.1016/j.jclepro.2020.125465

[13] Groppi, D., Pfeifer, A., Garcia, D. A., Krajačić, G., \& Duić, N. (2021). A review on energy storage and demand side management solutions in smart energy islands. Renewable and Sustainable Energy Reviews, 135(April 2020). https://doi.org/10.1016/j.rser.2020.110183

[14] Olabi, A. G., Onumaegbu, C., Wilberforce, T., Ramadan, M., Abdelkareem, M. A., \& Al - Alami, A. H. (2021). Critical review of energy storage systems. Energy, 214, 118987. https://doi.org/10.1016/j.energy.2020.118987

[15] Rabaia, M. K. H., Abdelkareem, M. A., Sayed, E. T., Elsaid, K., Chae, K. J., Wilberforce, T., \& Olabi, A. G. (2021). Environmental impacts of solar energy systems: A review. Science of the Total Environment, 754, 141989. https://doi.org/10.1016/j.scitotenv.2020.141989 